\title{
HOTAIR: A Promising Long Non-coding RNA with Potential Role in Breast Invasive Carcinoma
}

\author{
Niloofar Avazpour ${ }^{1}$, Mohammadreza Hajjari ${ }^{\text {1* }}$ and Maryam Tahmasebi Birgani ${ }^{2}$ \\ ${ }^{1}$ Department of Genetics, Faculty of Science, Shahid Chamran University of Ahvaz, Ahvaz, Iran, ${ }^{2}$ Department of Medical \\ Genetics, School of Medicine, Ahvaz Jundishapur University of Medical Sciences, Ahvaz, Iran
}

Keywords: HOTAIR, long non-coding RNA, gene expression, cancer, breast invasive carcinoma

\section{OPEN ACCESS}

Edited by:

Sanjeev Kumar Srivastava, Mitchell Cancer Institute,

United States

Reviewed by:

Shubhanchi Nigam,

University of Pittsburgh, United States

Lihua Li,

University of Minnesota, United States

Vijay Kumar Prajapati,

Central University of Rajasthan, India

*Correspondence:

Mohammadreza Hajjari

mohamad.hajari@gmail.com;

m-hajari@scu.ac.ir

Specialty section:

This article was submitted to

RNA

a section of the journa

Frontiers in Genetics

Received: 19 June 2017 Accepted: 19 October 2017

Published: 21 November 2017

Citation:

Avazpour N, Hajjari M and Tahmasebi Birgani M (2017) HOTAIR: A Promising Long Non-coding RNA with Potential

Role in Breast Invasive Carcinoma.

Front. Genet. 8:170.

doi: 10.3389/fgene.2017.00170
The majority of the Human genome is transcribed into a large number of non-coding RNAs (ncRNAs) which have different roles in the cell (Haemmerle and Gutschner, 2015). Long non-coding RNAs (LncRNAs) constitute a heterogeneous group of the ncRNAs that are longer than $200 \mathrm{nt}$. They are usually capped and poly-adenylated like mRNAs (Esteller, 2011; Fritah et al., 2014). Accumulating evidence show that the lncRNAs play an important role in cancer progression. So, these molecules have been considered as potential biomarker and therapeutic targets (Hajjari and Khoshnevisan, 2013; Hajjari et al., 2013b; Huarte, 2015).

One of the well-known lncRNAs is HOTAIR (HOX transcript antisense RNA) which is known to effect on the chromatin structure (Cao, 2014; Huang et al., 2014). This trans-acting lncRNA has different target loci including tumor suppressor genes. It recruits the PRC2 and LSD1 complexes in order to repress the transcription of target genes (Hajjari and Salavaty, 2015).

Owing to this regulatory mechanism, lots of the studies reported the role of HOTAIR in progression of different cancers such as breast, colon, and gastric cancer (Reviewed in Hajjari et al., 2013a, 2014; Hajjari and Salavaty, 2015). Gupta et al. found the dysregulation of this long transcript in breast tumors (Gupta et al., 2010). Then, other studies showed the importance of the HOTAIR in poor prognosis, metastasis, invasion, and short overall survival of breast cancer. Alves et al. indicated the potential role of HOTAIR in EMT progression and cancer stem cell features (Pádua Alves et al., 2013). Also, Gökmen-Polar et al. showed the HOTAIR as a marker for lymphatic metastases in ER-negative patients (Gökmen-Polar et al., 2015). However, the results are in contrast to the results of Sorensen et al but are similar to those reported by Lu et al. (Sørensen et al., 2013; Liu et al., 2014).

There are just a few studies with limited number of samples indicating the differentiated expression of HOTAIR in breast tumors compared to normal tissues. We believe that the differential expression of HOTAIR may indicate the potential role of this lncRNA in cancer initiation and progression. This study was aimed to highlight the potential role of HOTAIR in breast cancer. In this study, we analyzed the HOTAIR expression in breast invasive carcinoma tissues derived from TCGA (The Cancer Genome Atlas) which applies RNA sequencing of large cohorts. We also validated our data in different GEO dataset. The results can highlight the role of HOTAIR in breast invasive cancer and provide the viewpoint for further analyses of HOTAIR in breast cancer progression.

For this study, The Cancer Genome browser database (https://genome-cancer.ucsc.edu/), which uses the TCGA data, was used to analyze the association between HOTAIR expression level and features of breast invasive carcinoma. "BRCA gene expression (Illumina Hiseq Percentile)" data was selected for our analysis. The expression of HOTAIR was compared between the tumor $(n=1,066)$ and normal samples $(n=133)$ of TCGA tissues. Besides, the association between HOTAIR expression level of breast tissues and ER/PR/HER2 status of tumor tissues was also checked. 




FIGURE 1 | Heatmap displays the comparison between the HOTAIR expression of breast tumors and solid normal tissues. The data heatmap displays the normalized gene expression in red $(Z>0)$ and blue color $(Z<0)$. The HOTAIR is overexpressed in breast tumor tissues (A part of the tissues are shown as blue subgroup in right column) compared to normal tissues (shown as pink subgroup in right column). Data is derived from Cancer genome browser database.

TABLE 1 | The Up-regulation of HOTAIR in breast cancer samples (case) compared to normal samples (controls) in different GEO datasets.

\begin{tabular}{|c|c|c|c|}
\hline Dataset & Case (N) & Control (N) & $P$-value \\
\hline \multirow[t]{3}{*}{ GSE58135 } & $\begin{array}{l}\text { Triple negative Breast } \\
\text { cancer (42) }\end{array}$ & $\begin{array}{l}\text { Adjacent breast } \\
\text { tissues }(21)\end{array}$ & $8.75 E-8$ \\
\hline & $\begin{array}{l}\text { Breast cancer cell } \\
\text { lines (28) }\end{array}$ & $\begin{array}{l}\text { Adjacent breast } \\
\text { tissues }(21)\end{array}$ & $5.78 \mathrm{E}-6$ \\
\hline & $\begin{array}{l}\text { ER+/HER2- Breast } \\
\text { cancer primary } \\
\text { tumors (42) }\end{array}$ & $\begin{array}{l}\text { Adjacent breast } \\
\text { tissues }(21)\end{array}$ & $2.94 \mathrm{E}-6$ \\
\hline GDS2618 & Cancer cell lines (9) & $\begin{array}{l}\text { Normal breast cell } \\
\text { line (3) }\end{array}$ & 0.00024 \\
\hline GDS3853 & Ductal carcinoma (14) & Healthy breast (5) & $<0.0001$ \\
\hline GSE69240 & $\begin{array}{l}\text { High grade ductal } \\
\text { carcinoma in situ (25) }\end{array}$ & $\begin{array}{l}\text { Normal breast } \\
\text { organoids (10) }\end{array}$ & $1.92 \mathrm{E}-8$ \\
\hline GSE48408 & High metastasis (82) & Low metastasis (82) & 0.0076 \\
\hline
\end{tabular}

For validation study, the expression of HOTAIR gene was analyzed between breast tumor and normal tissues in different GEO datasets and profiles including GSE58135, GDS2618, GDS3853, GSE69240, GSE48408 through NCBI as well as Nexus expression database (http://syslab4.nchu.edu.tw/).

\section{REFERENCES}

Cao, J. (2014). The functional role of long non-coding RNAs and epigenetics. Biol. Proced. Online 16:42. doi: 10.1186/1480-9222-16-11

Esteller, M. (2011). Non-coding RNAs in human disease. Nat. Rev. Genet. 12:861. doi: $10.1038 / \operatorname{nrg} 3074$

Fritah, S., Niclou, S. P., and Azuaje, F. (2014). Databases for lncRNAs: a comparative evaluation of emerging tools. RNA 20, 1655-1665. doi: $10.1261 /$ rna.044040.113
Normalized expression ( $Z$ score) derived from TCGA tissues of cancer genome browser were compared between groups of study. The statistical analysis was done by $t$-test through R-software integrated in cancer genome browser. The $P$-value $<0.05$ were considered as significant $P$-value. Expression analysis between breast invasive tumor and normal tissues showed that the HOTAIR is significantly overexpressed in breast tumors compared to normal tissues (Figure 1). Categorizing the samples based on the HER2/PR/ER status demonstrated that HOTAIR is significantly over expressed in HER2 positive samples compared to negative ones. Additionally, in comparison with ER and PR positive tumors, HOTAIR is up-regulated in ER and PR negative tumors. It was found that the expression of HOTAIR is down-regulated in LuminalA, LuminalB, and normal like breast tumors subtypes (Data not shown).

Different GEO dataset and profiles were analyzed in order to compare the HOTAIR expression level between tumor and normal samples. The expression level between tumor and normal tissues were compared by $t$-test through GraphPad software. The data showed that the HOTAIR is significantly up-regulated in cancer cell lines and tumor tissues compared to normal breast samples (Table 1). To our knowledge, this is the first integrative study highlighting the over expression of HOTAIR in breast invasive carcinoma in a large cohort and different data sets. Since the breast cancer is a heterogeneous disease, the predictive power of current biomarkers is sometimes limited. So, there is a need to identify additional prognostic and predictive molecular biomarkers. The aim of this study was to examine the significance of the HOTAIR gene expression in breast cancer. Given the importance of HOTAIR in breast cancer, it promises as a potential biomarker and therapeutic target. However, because of the follow up limitations of TCGA cohort, further studies are necessary to reveal the role of HOTAIR in breast cancer initiation/progression in different cohorts with well annotation for tumor histology, and survival data.

\section{AUTHOR CONTRIBUTIONS}

All authors listed have made a substantial, direct and intellectual contribution to the work, and approved it for publication.

\section{ACKNOWLEDGMENTS}

We thank Shahid Chamran University of Ahvaz for supporting this study.

Gökmen-Polar, Y., Vladislav, I. T., Neelamraju, Y., Janga, S. C., and Badve, S. (2015). Prognostic impact of HOTAIR expression is restricted to ER-negative breast cancers. Sci. Rep. 5:8765. doi: 10.1038/srep08765

Gupta, R. A., Shah, N., Wang, K. C., Kim, J., Horlings, H. M., Wong, D. J., et al. (2010). Long noncoding RNA HOTAIR reprograms chromatin state to promote cancer metastasis. Nature 464:1071. doi: 10.1038/nature08975

Haemmerle, M., and Gutschner, T. (2015). Long non-coding RNAs in cancer and development: where do we go from here? Int. J. Mol. Sci. 16, 1395-1405. doi: 10.3390/ijms16011395 
Hajjari, M., and Salavaty, A. (2015). HOTAIR: an oncogenic long non-coding RNA in different cancers. Cancer Biol. Med. 12:1. doi: 10.7497/j.issn.2095-3941.2015.0006

Hajjari, M., and Khoshnevisan, A. (2013). Potential long non-coding RNAs to be considered as biomarkers or therapeutic targets in gastric cancer. Front. Genet. 4:210. doi: 10.3389/fgene.2013.00210

Hajjari, M., Behmanesh, M., Sadeghizadeh, M., and Zeinoddini, M. (2013a). Up-regulation of HOTAIR long non-coding RNA in human gastric adenocarcinoma tissues. Med. Oncol. 30:670. doi: 10.1007/s12032-013-0670-0

Hajjari, M., Khoshnevisan, A., and Shin, Y. K. (2013b). Long non-coding RNAs in hematologic malignancies: road to translational research. Front. Genet. 4:250. doi: 10.3389/fgene.2013.00250

Hajjari, M., Khoshnevisan, A., and Shin, Y. K. (2014). Molecular function and regulation of long non-coding RNAs: paradigms with potential roles in cancer. Tumor Biol. 35, 10645-10663. doi: 10.1007/s13277-014-2636-Z

Huang, J., Zhou, N., Watabe, K., Lu, Z., Wu, F., Xu, M., et al. (2014). Long non-coding RNA UCA1 promotes breast tumor growth by suppression of p27 (Kip1). Cell Death Dis. 5:e1008. doi: 10.1038/cddis.2013.541

Huarte, M. (2015). The emerging role of lncRNAs in cancer. Nat. Med. 21:1253. doi: $10.1038 / \mathrm{nm} .3981$

Liu, X. H., Sun, M., Nie, F. Q., Ge, Y. B., Zhang, E. B., Yin, D. D., et al. (2014). Lnc RNA HOTAIR functions as a competing endogenous RNA to regulate
HER2 expression by sponging miR-331-3p in gastric cancer. Mol. Cancer 13:92. doi: 10.1186/1476-4598-13-92

Pádua Alves, C., Fonseca, A. S., Muys, B. R., de Barros e Lima Bueno, R., Bürger, M. C., Souza, J. E., et al. (2013). Brief report: the lincRNA Hotair is required for epithelial-to-mesenchymal transition and stemness maintenance of cancer cell lines. Stem Cells 31, 2827-2832. doi: 10.1002/ stem. 1547

Sørensen, K. P., Thomassen, M., Tan, Q., Bak, M., Cold, S., Burton, M., et al. (2013). Long non-coding RNA HOTAIR is an independent prognostic marker of metastasis in estrogen receptor-positive primary breast cancer. Breast Cancer Res. Treat. 142, 529-536. doi: 10.1007/s10549-013-2776-7

Conflict of Interest Statement: The authors declare that the research was conducted in the absence of any commercial or financial relationships that could be construed as a potential conflict of interest.

Copyright (C) 2017 Avazpour, Hajjari and Tahmasebi Birgani. This is an open-access article distributed under the terms of the Creative Commons Attribution License (CC $B Y)$. The use, distribution or reproduction in other forums is permitted, provided the original author(s) or licensor are credited and that the original publication in this journal is cited, in accordance with accepted academic practice. No use, distribution or reproduction is permitted which does not comply with these terms. 